\title{
ESTADO, EDUCAÇÃO ESCOLAR E CURRÍCULO: EM DEFESA DA PRÁXIS TRANSFORMADORA
}

\author{
Bruna da Silva Duarte ${ }^{1}$ \\ Adreana Dulcina Platt ${ }^{2}$
}

\section{INTRODUÇÃO}

A educação escolar tem por base um currículo e corresponde a uma finalidade: a sociedade. Dado que a escolarização pública é orientada/organizada pelo Estado, cabe compreender este último, considerando que vivemos em uma organização sócio-política econômica capitalista, na qual, o individualismo e o lucro são os princípios fundantes e mantenedores.

O acesso à escola, segundo a Constituição Federal (BRASIL, 1988) deve ser garantido pelo Estado de forma gratuita, laica e com etapa obrigatória $^{3}$, no entanto não podemos considerar que somente a entrada na instituição escolar seja suficiente, muito pelo contrário, dado que esta deve atender aos anseios da classe trabalhadora.

Esta obrigatoriedade se deve objetivamente à construção da identidade nacional desde a mais tenra idade, e aos bens da cultura humana. Historicamente a escola pública tem servido ao atendimento da população brasileira de menor renda, e deve fazê-lo no sentido de instrumentalizá-la à práxis social revolucionária. Se a escola pública deve atender a todos, podemos encontrar na escola uma interlocução entre os dilemas sociais de classe e a formação da identidade nacional?

Compreendemos, assim, que a escola de qualidade para a classe trabalhadora não será a mesma escola de qualidade que se constitui para a classe dominante, dada a necessidade histórica de uma educação

\footnotetext{
${ }^{1}$ Graduanda do curso de Pedagogia pela Universidade Estadual de Londrina (UEL). Integrante do projeto de pesquisa "Análise Histórico-crítica dos eixos filosóficos do Projeto PolíticoPedagógico (PPP): a visão de sociedade, a visão de ser humano, a visão de educação e a função social da escola." E-mail: bruduarte51@gmail.com.

${ }^{2}$ Pós Doutora em Ciência Humanas pela UFSC. Professora Associada da Universidade Estadual de Londrina (UEL). E-mail: adplatt@uel.br

${ }^{3} \mathrm{Em} 1988$ esta etapa correspondia ao Ensino Fundamental, em 2009 alterada pela Emenda Constitucional №59/2009 (BRASIL, 2009) passa a comtemplar sujeitos de 4 a 17 anos.
} 
transformadora para a primeira e, ao contrário compreendendo que os estudantes da classe dominante serão formados para a reprodução e manutenção das desigualdades sociais produzidas pelo sistema capitalista. (COELHO, 1986; MELLO, 2007)

Para analisar o tema proposto recorremos a uma revisão de literatura cujo núcleo de recorte e análise será a partir do Materialismo Histórico Dialético. O Estado será o eixo institucional discutido a partir da análise de inúmeros autores clássicos, mas centralmente nos deteremos nas perspectivas de Aristóteles (1985) na alusão do surgimento da democracia, em Rousseau (2002) que retoma ideias da Grécia antiga e é uma das bases para a revolução burguesa e, em Marx e Engels (2006) que discutem as bases do sistema capitalista na orientação dos aparelhos de Estado. Destacaremos ainda a Constituição Federal (BRASIL, 1988) para demonstrar que o Estado observa as vozes e os interesses do capital, representando as minorias e o bem comum vinculado aos interesses de classes, mantendo as desigualdades consequentes do sistema capitalista. No interior da instituição escolar isso se reflete em currículos reprodutivistas, por isso, pautamo-nos na analogias feitas por Alves (1986) e autores como Chauí (2012), Coelho (1986), Severino (1986) e Duarte e Saviani (2012) para explanar uma perspectiva de superação aos padrões impostos pelo capitalismo no interior da escola.

Nesta perspectiva, consideramos que investigações referente às condições e aos determinantes que atrelam os interesses do Estado e os interesses da população de baixa renda devam ser realizadas para apurar se tais propósitos coadunam em relação ao trabalho político-pedagógico (o currículo em ação) nas unidades de ensino, de modo a realizar com satisfação e a ambos os envolvidos um trabalho pedagógico que se sustenta no princípio da práxis transformadora.

Nosso trabalho pretende esclarecer que Estado é esse na sociedade atual, que educação ele propõe, e ainda, qual currículo faz jus as intenções do mesmo. Para isto, iniciamos desnaturalizando o conceito de Estado, após apresentamos a educação e o currículo que corresponde a sociedade atual e, por fim destacamos o papel do profissional da educação com vistas a uma práxis transformadora neste contexto. 


\section{CONCEPÇÃO DE ESTADO}

O Estado é uma instituição discutida por inúmeros autores clássicos, no entanto, nos deteremos na leitura de Aristóteles (1985) que alude da era do surgimento da democracia, assim como Rousseau (2002) iluminista que retoma ideias da Grécia antiga e é uma das bases para a revolução burguesa. Para finalizar, apresentaremos a tese de Marx e Engels (2006) na discussão às bases do sistema/sociedade do capital e sua vinculação ao Estado.

O Estado é a entidade política que representa a nação; é a representação do povo por meio do sufrágio universal; é o sistema de regras e valores morais, sociais e políticos, que dão forma a uma nação. Cabe a este assegurar os direitos dos cidadãos previstos na Constituição Federal. O Art. $1^{\circ}$ caracteriza o Estado Nacional da seguinte forma:

\footnotetext{
A República Federativa do Brasil, formada pela união indissolúvel dos Estados e Municípios e do Distrito Federal, constitui-se em Estado democrático de direito e tem como fundamentos:

I - a soberania;

II - a cidadania;

III - a dignidade da pessoa humana;

IV - os valores sociais do trabalho e da livre iniciativa;

V - o pluralismo político. (BRASIL, 1988, p.5)
}

Neste sentido, está previsto na Constituição Federal que "[...] 0 poder emana do povo, que o exerce por meio de representantes eleitos ou diretamente, nos termos desta Constituição" (BRASIL, 1988, p.5), este representante, deve então, ter por objetivo o bem comum/coletivo acima dos interesses individuais. Mas será que os representantes efetivamente representam os interesses coletivos?

Aristóteles (1985, p.13), escreve que "[...] toda cidade é uma espécie de comunidade, e toda comunidade se forma com vistas a algum bem, pois todas as ações de todos os homens são praticadas com vistas ao que thes parece um bem [...]", deste modo, a união de sujeitos que forma um Estado deve visar independente de qualquer coisa o bem comum, pois foi com base neste princípio que estes indivíduos se uniram, senão não haveria necessidade de formar uma comunidade. Observa-se, também, que segundo Aristóteles (1985) não pode haver um único governante, mas sim, toda a comunidade que 
governe, mesmo que haja um governante eleito, todos os sujeitos da comunidade devem participar para que seja alcançado o bem comum. Nesta perspectiva, podemos dizer que o bem comum depende para além do representante, ele só será alcançado quando todos se comprometerem para que esta finalidade seja alcançado.

Ao contrário do que presenciamos atualmente, Aristóteles argumentava que um Estado só se constituía como tal, se todos os sujeitos participassem de forma ativa, visando o bem comum. Atualmente, porém, elegesse um governante, e este por nem sempre estar para representar o povo, mas o interesse de uma minoria, governa em prol do favorecimento de interesses individuais. Onde o velho jargão "Política e Religião não se discutem" mantem o ato participativo preso ao voto, situação que exacerba com a falta do sentimento de pertença, que promovida pelo pensamento individualista "eu faço minha parte", mas e se todos fizéssemos juntos?

Marx e Engels (2006) apontam que a sociedade se transforma no coletivo dos homens, de modo que um homem sozinho não faz história, mas o coletivo sim. A falta de interesse e participação dos sujeitos que compõem o Estado, os torna governados, de maneira alienada e indifente ao bem comum, no entanto, essa situação é mais uma consequência da ação da ideologia dominante, da qual a escola pública torna-se instrumento. (ALTHUSSER, 1985; CHAUÍ, 1980; SEVERINO, 1986)

Para Rousseau (2002, p.26), o Estado é

[...] um corpo moral e coletivo, [...] o qual recebe desse mesmo ato sua unidade, seu eu comum, sua vida e sua vontade. A pessoa pública, formada assim pela união de todas as outras, tomava outrora o nome de cidade, e toma hoje o de república ou corpo político, o qual é chamado por seus membros: Estado, quando é passivo; soberano, quando é ativo; autoridade, quando comparado a seus semelhantes. No que concerne aos associados, adquirem coletivamente o nome de povo, e se chamam particularmente cidadãos, na qualidade de participantes na autoridade soberana, e vassalos, quando sujeitos às leis do Estado.

Deste modo, o autor descreve o Estado sob a égide burguesa, que se materializa após a revolução de 1789, e mesmo colocando os cidadãos em duas categorias, não está criticando esta forma de organização, mas sim, indicando que desta forma todos são iguais e livres, e estão unidos pelo bem 
comum, que seriam "igualdade, liberdade e fraternidade". Logo, mesmo que o Estado seja composto pelos sujeitos individuais, estes são sujeitos porque devem dominados pelo mesmo, estando o primeiro contra os segundos.

Neste contexto, Marx e Engels (2006) apontam que o Estado atende apenas aos interesses do capital, sendo representante da minoria, onde "[...] o Estado adquiriu uma existência particular a par, e fora, da sociedade civil; mas ele nada mais é do que a forma de organização que os burgueses se dão, tanto externa como internamente, para garantia mútua da sua propriedade e dos seus interesses." (MARX E ENGELS, 2006, p.7). Busca-se, assim, o bem comum aos interesses dos que fazem parte da classe dominante, mantendo as desigualdades consequentes do sistema capitalista aparentemente sem solução.

\section{ESTADO, ESCOLA E CURRÍCULO}

No texto "Currículo dos Urubus: Pinóquio às avessas", Ruben Alves (1986), faz brilhante analogia da educação atual com a história de Pinóquio, mas às avessas, em que "[...] contando sobre o destino invertido daqueles que eram de carne e osso ao entrar na escola e só recebem diplomas depois de se transformarem em bonecos de pau." (p.9)

Para refletir sobre a escola e o currículo que o Estado oferece se faz primordial desnaturalizar as condições importas a educação institucionalizada atualmente. De modo que, se inicialmente a analogia supracitada aparenta loucura, quando analisada cuidadosamente se fez presente em toda a realidade educacional. $O$ autor apresenta que o currículo estabelece o que os "[...] mestres iriam ensinar e os discípulos iriam aprender." (ALVES, 1986, p.9)

No entanto, currículo e a escola corresponderão as intenções que materializem os interesses do Estado. É importante pensar que para este último, dado seus interesses burgueses, o que influi são resultados e a classificação do educandos, sendo assim aquele que segue a risca o que por ele é indicado é premiado. Mas será que a nota é capaz de resumir o quanto um aluno aprendeu?

Ou ele mantém os alunos na mediocridade, pois a media 6 é suficiente para ser aprovado, mas e os outros 4? Não são importantes? 
Rubens Alves (1986), quando afirma que a mediocridade do pato o fez superior na estatística final, faz exatamente a analogia a questão da valorização das notas. $O$ pato não era superior a nenhum outro animal, mas sua média era a maior.

É preciso desmistificar que a nota seja sinônimo de melhor aluno. O currículo deve ser organizado com vistas que todos adquiram os conhecimentos sistematizados histórico e socialmente pela humanidade, entretanto não deve ter por base a classificação dos estudantes, pois todos têm condição de aprender, e o professor não pode ficar preso ao aluno que caminha sozinha, ele deve mediar o conhecimento àquele que precisa. Pensemos assim: se a nota resume o bom aluno e o mau aluno, e este último fica com 3 de média em um bimestre, o que aconteceu que ele não apropriouse dos outros conhecimentos que totalizam 7 ? Ou ainda, será que ele realmente não sabia nada sobre o conteúdo, ou a forma avaliativa não foi suficiente para que ele demonstrasse o que sabia?

Mas, afinal quem ganha com a classificação dos estudantes na escola? Ganham os detentores dos meios de produção que podem escolher o que melhor atinge a suas necessidades no mercado de trabalho e apenas isso. Aqui já demonstramos o que nos propomos inicialmente a discutir: a escola e 0 currículo que o Estado oferece a maioria da população. Enfatizando a mediocridade como algo bom, levando todos a tornarem-se massa, a ser utilizada a bel interesse para manutenção do status quo de poucos, tanto como mão de obra, quanto como consumidores de seus produtos.

Contudo, dada a relação dialética inerente a sociedade atual, onde os antagônicos coexistem, mesmo que o capitalismo seja dominante, ele aindaé apenas dominante, e fato de vivermos em uma democracia, que é a única organização social que o conflito é considerado legítimo, encontramos na escola, uma outra possibilidade para além da reprodução do sistema capitalista, existe em seu interior a possibilidade de práxis transformadora. (CHAUÍ, 2012; COELHO, 1986; SEVERINO, 1986)

Ainda que na forma da lei a Educação e a Escola oferecidas pelo Estado devam ser de qualidade, e enfatizar uma educação cidadã, já que vivemos em uma democracia, pagamos impostos e é um direito de todos previsto na Constituição Federal de 1988, o Estado está contra o sujeito e em 
prol dos interesses da classe dominante. Desta forma, a escola garantida por este será a que atenda aos demandas dessa classe, e seu currículo corresponderá as necessidades da mesma. Se a escola pública foi instituída como direito, tanto para o bem da classe trabalhadora (possibilita o acesso ao conhecimentos humanos de forma sistematizada), quanto para seu mal (a escola a serviço do capital).

No entanto, a contradição presente na escola a partir da transmissão dos conhecimentos humanos sistematizados ao longo da história, pois essa é a possibilidade de mudança em seu interior, de forma que, a aquisição destes conteúdos é base para a transformação da sociedade e, ainda estes são parte constituinte dos meios de produção e estão em poderio do capital. (DUARTE; SAVIANI, 2012) Logo, mesmo com a possibilidade de a escola pública ser utilizada como instrumento ideológico do Estado, ainda assim, sua existência é mais que justificada, pois também é em seu interior que existe a possibilidade de conscientizar coletivamente a classe trabalhadora, para sua união e concomitante luta em torno de seus interesses comuns como classe, vislumbrando que uma das ações necessárias a efetiva transformação da sociedade é a tomada dos processos de produção. (SEVERINO, 1986; ALTHUSSER, 1985)

\section{CONSIDERAÇÕES FINAIS: OS EDUCADORES NA LUTA!}

E os educadores onde entram nessa história? Entram na reprodução dos padrões do Estado para a educação e o currículo. É necessário superar a ideia de que o Estado é bondoso, que os padrões são o ideal. Não cabe mais nas escolas públicas que continue a se reproduzir práticas que beneficiam apenas a $1 \%$ da população. A luta pela mudança deve ser de todos os envolvidos no processo educativo, todos somos parte constituinte, logo se deixe o Estado achar que manda, o importe é que a escola esteja para a classe trabalhadora.

A mudança tão esperada por todos os envolvidos no processo educativo não acontecerá de cima para baixo, para que ela ocorra todos os envolvidos no processo educativo devem assumir seu compromisso com o verdadeiro bem comum e lutar. Sem luta coletiva, nada será transformado. 
É necessário, ainda, que os estudantes sejam respeitados, avaliados de acordo com seu processo e desenvolvimento, utilizando vários instrumentos avaliativos, com vistas a aquisição das máximas habilidades humanas e não pela mera classificação. É importante que o estudante ao apropriar do conhecimento além de fazer uso do mesmo, possa também refletir sobre o mesmo e até mesmo refuta-lo.

O conhecimento é imprescindível à vida, mas ele não é constante e imutável. Sua aquisição é um direito de todos, e também, é base para a práxis transformadora, de modo a viabilizar a transformação do meio e das determinações reais de vida. Haja visto que o trabalho intelectual está intrínseco ao trabalho manual, de modo que, o trabalho é resultado da ação humana que transforma o meio, o outro e a si mesmo. (VAZQUEZ, 1977)

O educador deve possibilitar ao estudante expressar seu entendimento e não prendê-lo a simples cópia e reprodução. De modo que, a imaginação, a criatividade, a iniciativa, a criticidade, a consciência, a reflexão, sejam base para as atividades organizadas no interior da escola. Fugir dos padrões alienantes e engessantes é necessário a transformação da prática educativa no interior da instituição escolar rumo a uma educação que seja de qualidade para a classe trabalhadora. A educação não muda a sociedade, mas pode instrumentalizar os sujeitos à mudança, que só acontecerá se ocorrer de forma coletiva.

\section{REFERÊNCIAS}

ALTHUSSER, Louis. Ideologia e Aparelhos ideológicos de Estado. Tradução: Valter José Evangelista e Maria Laura Viveiros de Castro. Rio de Janeiro, RJ: Graal, 1985.

ARISTÓTELES. A Política. Tradução: Mário da Gama Kury. Brasília, DF: Editora Universidade de Brasília, 1985.

BRASIL. Constituição da República Federativa do Brasil. 1988. Disponível em: <http://www.senado.gov.br/legislacao/const/con1988/CON1988_05.10.1988/C ON1988.pdf> Acesso em: 15 de ago. de 2013

BRASIL. Emenda constitucional no 59 de 11 de novembro de 2009. Diário Oficial da União, Brasília, 12 de novembro de 2009. 
CHAUÍ, Marilena. "Ideologia e Educação". Educação \& Sociedade, jan./1980, no.5, p.24-40.

. Democracia e sociedade autoritária. Comunicação \& Informação, jul./dez. 2012, vol.15, no. 2, p.149-161.

COELHO, Ildeu Moreira. A Questão Política do Trabalho Educativo. In: BRANDÃO, Carlos Rodrigues (Org.). O Educador: Vida e Morte. Rio de Janeiro, RJ: Edições Graal, 1986.

DUARTE, Newton; SAVIANI, Dermeval. Pedagogia Histórico-Crítica e a Luta de Classes na Educação Escolar. Campinas, SP: Autores Associados, 2012.

MARX, Karl; ENGELS, Friedrich. Feuerbach: Oposição das Concepções Materialista e Idealista. In: . A Ideologia Alemã. 2006. Disponível em: <http://www.marxists.org/portugues/marx/1845/ideologiaalemaoe/cap4.htm\#top p> Acesso em: 10 jan. 2015.

MELLO, Suely Amaral. As Práticas Educativas e as Conquistas de Desenvolvimento das Crianças Pequenas. In: RODRIGUES, Elaine; ROSIN, Sheila Maria (Orgs). Infância e Práticas Educativas. Maringá, PR: Eduem, 2007.

ROUSSEAU, Jean-Jacques. Do Contrato Social. Tradução: Orlando Roque da Silva. Edição eletrônica: Ed. Ridendo Castigat Moraes. 2002.

SEVERINO, Antônio Joaquim. Educação, Ideologia e Contra-Ideologia. São Paulo, SP: EPU, 1986.

VAZQUEZ, Adolfo Sanchez. Filosofia da Práxis. Tradução: Luiz Fernando Cardoso. Rio de Janeiro, RJ: Paz e Terra, 1977. 